\title{
Skolforskningsinstitutet, konfigurativa översikter och undervisningens komplexitet
}

Magnus Levinsson

Sektionen för pedagogisk utveckling och forskning, Högskolan i Borås

\begin{abstract}
Kraven på evidensbaserad utbildning har drivit fram en rad initiativ som avser att minska det förmodade gapet mellan forskning, politik och praktik. Bland dessa initiativ finns etableringen av särskilda organisationer-så kallade mäklarorganisationer-med uppgift att syntetisera resultaten av utbildningsvetenskaplig forskning. I Sverige har Skolforskningsinstitutet inrättats för att genomföra systematiska översikter inom skolans och förskolans område. Skolforskningsinstitutet ska ge lärare bättre förutsättningar att undervisa med stöd av vetenskapligt underbyggda metoder och arbetssätt. Kritiker hävdar dock att mäklarorganisationer överlag prioriterar aggregativa översikter för att utvärdera effekterna av interventioner och att denna inriktning är mindre passande för komplexa områden som utbildning. I ljuset av Skolforskningsinstitutets uppdrag och den kritik som riktats mot systematiska översikter argumenterar jag i denna artikel för att institutets verksamhet bör inbegripa konfigurativa översikter. Konfigurativa översikter skulle ge Skolforskningsinstitutet bättre möjligheter att genomföra sitt uppdrag, framförallt eftersom konfigurativa format kan utarbetas för att: (1) understödja omdömen om vad som är utbildningsmässigt önskvärt; (2) inkludera studier från praktikutvecklande ansatser; samt (3) förmedla kunskap med potential att spela en kritisk roll i undervisningen.
\end{abstract}

\section{INLEDNING}

I början av 2015 påbörjade Skolforskningsinstitutet (SKOLFI) sin verksamhet inom utbildningsområdet i Sverige. Inrättandet av SKOLFI kan 
liksom etableringen av många andra liknande organisationer förklaras av ökade krav på evidensbasering inom skolans och förskolans område. En organisation av stor betydelse för spridningen av idén om evidensbaserad praktik inom utbildningssektorn är the Organisation for Economic Cooperation and Development ([OECD], 2007, 2003). OECD (2004a, 2004b) har bland annat utfört granskningar av medlemsländernas forsknings- och utvecklingssystem och kommit med rekommendationer angående hur dessa system kan överbrygga det förmodade gapet mellan forskning, politik och praktik. OECD har i detta sammanhang framförallt betonat vikten av att medlemsländerna inrättar särskilda organisationer-så kallade mäklarorganisationer - med uppgift att genomföra systematiska översikter av utbildningsvetenskaplig forskning. Mäklarorganisationen Danish Clearinghouse for Educational Research (DCU) grundades exempelvis 2006 som en direkt konsekvens av OECD:s granskning. Danmarks regering uppmanades att dra lärdom av motsvarande organisationer i anglosaxiska länder och att förbättra villkoren för experimentella studier inom utbildningssektorn (Hansen \& Rieper, 2009; Moos, 2006; OECD, 2004b).

I Sverige uppmärksammades betydelsen av mäklarorganisationer på allvar först 2009 i en statlig utredning (SOU 2009:94) som förordade en särskild funktion för att mer systematiskt kunna sprida forskning inom skolans och förskolans område. Utredningen rekommenderade i första hand ett nordiskt samarbete med DCU eftersom forskningen i Sverige ansågs otillräcklig för systematiska översikter. Frågan om en svensk mäklarorganisation kom dock upp på den politiska agendan igen efter PISA-chocken 2012. Alliansregeringen initierade kort därefter en ny utredning som specifikt fokuserade inrättandet av SKOLFI (U2014:02). Regeringsdirektiven (Dir. 2014:7) underströk i detta sammanhang behovet av att stärka kunskapen om "effektiva metoder och arbetssätt" för att "öka måluppfyllelsen och förbättra kunskapsresultaten" (s. 2). Från politiskt håll betonades alltså en funktion liknande den som OECD förordar och som är utmärkande för många andra mäklarorganisationer vilka nästan uteslutande genomför aggregativa systematiska översikter. Framstående exempel på organisationer som prioriterar aggregativa översikter är What Works Clearinghouse (u.å.) i USA och det internationella nätverket Campbell Collaboration (2014) som båda tillämpar en evidenshierarki där randomiserade kontrollförsök (RCT:er) tillskrivs en överordnad betydelse. Den aggregativa inriktningen har dock varit föremål för omfattande debatt och kritiker hävdar att den är mer passande för andra områden, som till exempel medicin, än för komplexa fält som utbildning och skola där verksamheten präglas av multipla mål, kontextbundenhet och lokal variation (Biesta, 2007; Bridges, 2008; Carlgren, 2010; Clegg, 2005).

SKOLFI:s uppdrag kom emellertid att bli avsevärt bredare än vad som betonades i regeringsdirektiven. Väl insatta i kritiken mot evidensbasering och 
systematiska översikter förespråkade ansvariga för utredningen av inrättandet av SKOLFI (U2014:02) en myndighetsinstruktion som hävdades svara mot skolans och förskolans uppdrag-1. Denna instruktion fastställdes sedermera $\mathrm{i}$ den förordning som reglerar SKOLFI:s verksamhet.

Skolforskningsinstitutet ska bidra till att de verksamma inom skolväsendet ges goda förutsättningar att planera, genomföra och utvärdera undervisningen med stöd av vetenskapligt underbyggda metoder och arbetssätt. Myndigheten ska bidra till goda förutsättningar för barns och elevers utveckling och lärande och till förbättrade kunskapsresultat för elever. (SFS 2014:1578, 1S)

SKOLFI har alltså ett förhållandevis brett uppdrag, som inte enbart omfattar förbättringar av kunskapsresultaten, vilket kan anses resa särskilda krav på institutets arbete med systematiska översikter. Utredningen av inrättandet av SKOLFI (U2014:02) betonar exempelvis att det krävs en bred uppsättning av metoder för att syntetisera utbildningsvetenskaplig forskning. Liknande slutsatser presenteras även av Vetenskapsrådets (2015) SKOLFORSKprojekt, som löpte parallellt med utredningen för att ge SKOLFI en bra start. I slutrapporten, som drar samman resultat från totalt 15 delprojekt, rekommenderas SKOLFI att dra lärdom av den metodutveckling som pågår. Två av delprojekten (Levinsson, 2015; Prøitz, 2015) betonar särskilt vikten av att institutet också genomför så kallade konfigurativa systematiska översikter för att kunna syntetisera utbildningsvetenskaplig forskning av skiftande karaktär. Konfigurativa angreppssätt framhålls i de båda delprojekten som centrala för SKOLFI:s uppdrag.

Att SKOLFI mot bakgrund av sitt uppdrag behöver arbeta med olika typer av översikter att har även betonats av myndigheten själv. Sedan uppstarten 2015 har SKOLFI fortlöpande informerat om det utvecklingsarbete som sker parallellt med genomförandet av institutets första översikter (t.ex. SKOLFI, 2015a, 2016a, 2016b). Som ett led i detta arbete har SKOLFI (2015b) blivit medlem i det internationella nätverket Evidence Informed Policy and Practice in Education in Europe Network (EIPPEE). SKOLFI (2016c) har också bildat ett nationellt nätverk för samverkan kring metodutveckling tillsammans med Statens beredning för medicinsk och social utvärdering (SBU) och Mistras råd för evidensbaserad miljövård (EviEM). Därutöver sker utbyte kring metodfrågor med enskilda mäklarorganisationer, där Evidence for Policy and Practice information and Co-ordinating Centre (EPPI) i Storbritannien betraktas som en viktig samverkanspart (SKOLFI, 2017). EPPI lyfts ofta fram som ledande inom fältet och centrets arbete med att utveckla metoderna för systematisk översikt, inte minst vad det gäller synteser för kvalitativ forskning, har ökat intresset för konfigurativa översikter (Bohlin, 
2010; Gough, Oliver \& Thomas, 2012a; Hansen \& Rieper, 2009; Levinsson \& Prøitz, 2017).

Levinsson och Prøitz (2017) studie av EPPI och DCU visar dock att konfigurativa översikter sällan används. Trots en uttalad ambition att genomföra översikter av olika slag domineras EPPI:s och DCU:s verksamhet inom utbildningssektorn av aggregativa syntesformat. Levinsson och Prøitz kunde inte identifiera en enda utpräglad konfigurativ översikt som inkluderade olika vetenskapliga traditioner, ansatser och metoder. När konfigurativa angreppssätt väl ingår i EPPI:s och DCU:s översikter så är de överlag mindre framträdande och underordnas som regel den aggregativa logiken för att svara på frågor om vad som fungerar (jfr Wendt, 2016).

I ljuset av SKOLFI:s uppdrag och den kritik som framförts mot systematiska översikter inom utbildningsområdet argumenterar jag i denna artikel för att delar av institutets arbete med systematiska översikter bör baseras på konfigurativa angreppssätt. Konfigurativa översikter skulle förbättra SKOLFI:s möjligheter att genomföra sitt uppdrag, framförallt genom att sådana syntesformat kan utarbetas specifikt för att: (1) understödja lärares omdömen om vad som är utbildningsmässigt önskvärt inom olika delar av skolans och förskolans verksamhet; (2) inkludera studier som genomförs inom ramen för praktikutvecklande ansatser; samt (3) förmedla kunskap som kan spela en kritisk roll i undervisningen. Viktigt att understryka är emellertid att dessa argumentationslinjer varken utesluter eller förnekar att de anförda förtjänsterna av konfigurativa format skulle kunna uppnås på andra, och kanske i vissa sammanhang mer ändamålsenliga sätt, exempelvis genom informella översikter eller primärstudier. Men givet utgångspunkten i SKOLFI:s uppdrag med systematiska översikter faller denna fråga utanför artikelns ramar att ta ställning till.

De kommande delarna av artikeln disponeras i fem avsnitt. Inledningsvis beskrivs översiktligt skillnaderna mellan aggregativa och konfigurativa syntesformat. Därefter följer tre delar som framför argument till varför SKOLFI bör genomföra konfigurativa översikter. Avslutningsvis diskuteras gränserna för konfigurativa översikter i förhållande till SKOLFI:s uppdrag.

\section{AgGREGATIVA OCH KONFIGURATIVA ÖVERSIKTER}

Användningen av systematiska översikter kan spåras tillbaka till utvecklingen av metaanalys, en metod för att aggregera data från kvantitativa studier som presenterades av Gene Glass och Mary Lee Smith under 70-talet (Bohlin, 2011). En uppmärksammad förtjänst med metaanalys är att data från ett stort antal studier omvandlas till ett enhetligt mått, så kallad effektstorlek, vilken möjliggör jämförelser mellan enskilda resultat och en sammanvägd effektstorlek (Gough, 2004). Metaanalys utgjorde tillsammans med RCT:er centrala komponenter i försöken att realisera visionen om evidensbaserad 
medicin under 90-talet (Bohlin, 2011). Inom evidensbaserad medicin har RCT:er betraktats som "the golden standard" för att utvärdera effekterna av interventioner (Petticrew \& Roberts, 2006; Torgerson, 2003). Användningen av metaanalys banade väg för utvecklingen av andra formaliserade syntesmetoder eftersom principerna för metaanalys ansågs vara lovande men inte tillämpliga på all sorts forskning (Bohlin, 2012). Beteckningen "systematisk översikt" kom sedermera att fungera som ett samlingsbegrepp för de olika metoder som utarbetades (Bohlin, 2011).

Baserat på grundbegreppen aggregering och konfigurering har Gough m.fl. (2012a, 2012b) utvecklat en typologi för att beskriva likheter och skillnader mellan olika syntesformat. Enligt Gough m.fl. vilar aggregativa översikter på antagandet om att de studerade fenomenen är relativt entydiga till sin karaktär. Aggregativa översikter kännetecknas av en deduktiv synteslogik som summerar eller adderar resultaten från liknande studier för att utvärdera effekterna av en intervention. Metoden i aggregativa översikter bestäms idealt a priori. Det betyder att processteg som litteratursökning, urval av studier, kvalitetsbedömning, extrahering och kodning av data, och syntes definieras i förväg (t.ex. O’Connor, Green \& Higgins, 2011). Två andra utmärkande drag är att litteratursökningen som regel är grundlig och baserad på en rad kompletterande sökstrategier, samt att kvalitetsbedömningen av inkluderade studier syftar till att undvika olika former av "bias" (t.ex. Campbell Collaboration, 2014; Higgins, Altman \& Sterne, 2011). Målet är att identifiera samtliga relevanta studier inom området för att säkerställa ett så representativt, homogent och tillförlitligt underlag som möjligt (Gough \& Thomas, 2012).

Konfigurativa översikter har istället lyfts fram som passande för att syntetisera komplexa forskningsfält, där olika ansatser och metoder för att studera en fråga öppnar för kvalitativt skilda förståelser av fenomenet (DixonWoods m.fl., 2006; Petticrew, 2015). Enligt Gough m.fl. (2012a, ss. 40-41) baseras konfigurativa översikter på antagandet om att fenomenen som studeras är mångtydiga till sin karaktär. Vad som fångas upp av en enskild undersökning antas bero på studiens metodologiska och teoretiska utgångpunkter (jfr Barnett-Page \& Thomas, 2009). Konfigurativa översikter följer en induktiv synteslogik som arrangerar resultaten på sätt som idealt ska utmynna $\mathrm{i}$ en meningsfull bild av vad forskningen säger inom ett givet område. Meta-etnografi (Noblit \& Hare, 1988) är ett exempel på ett konfigurativt angreppssätt som kan användas för att syntetisera kvalitativ forskning av olika karaktär. Andra beteckningar som har lanserats för konfigurativa metoder är meta-study (Paterson m.fl., 2001), meta-narrative (Greenhalgh m.fl., 2005) och critical interpretive synthesis (Dixon-Woods m.fl., 2006).

Konfigurativa översikter är jämfört med aggregativa översikter mer utforskande och iterativa till sin karaktär (Gough m.fl., 2012a, ss. 51-52). 
Detta kan ses i hur processtegen i konfigurativa översikter ofta upprepas och överlappar varandra. I vissa konfigurativa översikter kan till exempel kvalitetsbedömning och syntes gå in i varandra eftersom värdet av enskilda studier först antas bli synligt i ljuset av övrig forskning inom området. Som Gough m.fl. (2013) påpekar, "a spread of different and unusual cases may provide greater insights than a representative sample that reveals more about typical cases" (s. 20). Litteratursökning kan återkomma vid flera tillfällen under översiktsarbetet och principen om mättnad kan användas för att styra urvalet av studier. Målet är att identifiera tillräckligt många studier för att få till stånd en meningsfull konfiguration som har potential att fördjupa förståelsen av det undersökta fenomenet (jfr Petticrew, 2015).

Även om konfigurativa och aggregativa översikter har påtagliga skillnader är det viktigt att understryka att många översikter baseras på både konfigurativa och aggregativa element, och det finns översikter som kan placeras in mitt emellan de båda ytterligheterna (t.ex. Snilstveit, Oliver \& Vojtkova, 2012; Westhorp m.fl., 2014). Det är även så att aggregering av kvalitativa studier förekommer i vissa översikter, liksom konfigurering av kvantitativa studier i andra. Typologin som utvecklats av Gough m.fl. (2012a, 2012b) är ett försök att överbrygga dikotomin mellan kvalitativ och kvantitativ forskning.

\section{VAD ÄR UTBILDNINGSMÄSSIGT ÖNSKVÄRT?}

Motståndare till evidensbasering inom utbildningsområdet påtalar att det finns gränser för vilka delar av undervisningen som kan stödjas av aggregativa översikter och experimentella studier (Bridges, 2008; Donnelly, 1999; Hammersley, 2004). Biesta (2007) understryker därutöver att det är problematiskt att frågor gällande undervisningens effektivitet prioriteras. När undervisning på detta sätt likställs med en intervention menar Biesta att målen tenderar att tas förgivna och de separeras dessutom från medlen som antas kunna verka neutralt. En sådan instrumentell syn riskerar enligt Biesta ytterst att begränsa lärares inflytande över undervisningen, och Biesta argumenterar därför för ett bredare angreppssätt som också innefattar normativa och politiska frågor om vad som är utbildningsmässigt önskvärt.

If we really want to improve the relation between research, policy, and practice in education, we need an approach in which technical questions about education can be addressed in close connection with normative, educational, and political questions about what is educationally desirable. (s. 21-22)

Frågor om vad som är utbildningsmässigt önskvärt omfattar enligt Biesta (2007) såväl undervisningens mål som medel. Även om skolans och 
förskolans mål fastställs genom demokratiska processer betyder inte det att målen därmed kan tas förgivna. Vilka specifika innebörder av målen som är önskvärda bör enligt Biesta ständigt dryftas i den kontext där målen ska förverkligas. Sådana överläggningar behöver dessutom göras i nära anslutning till medlen. Biesta betonar att undervisningens genomförande alltid förmedlar budskap till eleverna oavsett vilka mål som de förväntas uppfylla. Hur lärare organiserar arbetet och samspelar med eleverna kan alltså prägla deras lärande och ibland på sätt som får undervisningen att framstå som mindre önskvärd. Biestas poäng är alltså att undervisning inte endast kan bedömas på grundval av hur "effektivt" den bidrar till förbestämda mål.

Om SKOLFI i enlighet med sitt uppdrag ska kunna ge lärare goda förutsättningar att bedriva undervisning framstår det i ljuset av Biestas argumentation som nödvändigt att utarbeta översikter som kan uppmuntra diskussion kring vad som är utbildningsmässigt önskvärt. Detta kräver dock översiktsfrågor som aggregativa format inte lämpar sig för eftersom dessa format, som Hammersley (2009) betonar, främst utmynnar i evidens för eller emot de arbetssätt och metoder som studeras. Konfigurativa översikter kan emellertid genomföras i syfte att utveckla ny teori och därigenom också understödja lärares omdömen om vad som är utbildningsmässigt önskvärt. Jag har i en debattartikel (Levinsson, 2017) använt Nilholm och Göranssons (2015) översikt av forskningen om inkludering för att illustrera denna potential. Översikten påminner om hur konfigurativa översikter framställs i litteraturen och skiljer sig därmed från de metaanalyser inom området som intresserar sig för effekterna av olika inkluderingsinsatser (t.ex. Elbaum, Vaughn, Hughes \& Moody, 1999; Swanson, m.fl., 2014). För lärare är det givetvis centralt att få insikt i tillvägagångssätt som är effektiva när det gäller att inkludera eleverna. Men en minst lika viktig fråga i sammanhanget är, för att återvända till Biesta (2007), vad som ska räknas som effektiv inkludering. För lärare är det alltså lika angeläget att begrunda vilket inkluderingsbegrepp som är önskvärt i förhållande till både uppdrag och villkor i den lokala praktiken.

Nilholm och Göranssons (2015) översikt inbegriper undersökningar av skiftande karaktär för att bland annat belysa vilken betydelse inkludering ges inom forskningen. Konfigurationen av studierna visar att inkludering rör allt från att placera elever i svårigheter i det vanliga klassrummet och att tillfredsställa kunskapsmässiga behov hos elever i svårigheter eller hos alla elever, till att skapa gemenskaper med specifika egenskaper. Mot denna bakgrund argumenterar Nilholm och Göransson för vikten av att verksamma inom skolväsendet tydliggör vad som avses med inkludering. Sammantaget framstår resultaten av översikten som ett relevant underlag för överläggningar om vilket inkluderingsbegrepp som är utbildningsmässigt önskvärt.

Med hjälp av konfigurativa översikter skulle SKOLFI på motsvarande sätt kunna öppna upp frågan om vad som är önskvärt inom andra delar av skolans 
och förskolans verksamhet. Detta kan gälla såväl det övergripande uppdraget som andra nivåer i styrkedjan där exempelvis ämnesspecifika aspekter hamnar i centrum. Medborgarfostran kan fungera som exempel för att belysa det förra (även om detta uppdrag också ska genomsyra undervisningen av enskilda ämnen). Inom detta område finns det, precis som i exemplet gällande inkludering, studier som belyser vilka arbetssätt och metoder som är effektiva. Geboers, Geijsel, Admiraal och ten Dams (2013) översikt inkluderar exempelvis studier av hur olika aktiviteter i och utanför skolan påverkar elevers medborgarfostran. Studierna betonar dock olika aspekter av medborgarfostran: socialt ansvarstagande, konflikthantering, bemötande av olikheter, samt demokratiskt handlande i en politisk och social mening (jfr Scott \& Lawson, 2001). För att hantera dessa skillnader inbegriper Geboers m.fl. (2013) översikt, som främst baseras på en aggregativ logik, konfigurativa element för att ordna studierna utifrån vad som avses med medborgarfostran. Resultaten ger bland annat stöd för att ett öppet klassrumsklimat som präglas av dialog mellan lärare och elever kan främja politiska dimensioner av medborgarfostran, främst elevers kompetenser, attityder och beteenden inom området. Enligt Geboers m.fl. saknas det forskning kring hur klassrumsklimat och dialog påverkar medborgarfostran i andra avseenden, liksom studier av hur sociala dimensioner kan gynnas. Den betydelse som medborgarfostran ges inom forskningen överskuggas dock till viss del av översiktens aggregativa inriktning. ${ }^{2}$ En utpräglad konfigurativ översikt hade på ett mer fördjupat sätt kunnat utforska olika innebörder av medborgarfostran och bildat ett rikare underlag för diskussion om vilka dimensioner som är önskvärda.

Avslutningsvis är det viktigt att understryka att konfigurativa översikter inte kan bestämma vad som är utbildningsmässigt önskvärt i skolans och förskolans verksamhet. Genom att designa konfigurativa översikter på det sätt som förordas ovan kan SKOLFI snarare bistå lärares omdömen på ett indirekt vis genom att öppna upp frågan om vad som är önskvärt. ${ }^{3}$ Detta ska dock inte betraktas som en nackdel beträffande uppdraget att ge lärare goda förutsättningar att undervisa. Det är just på denna punkt som mäklarorganisationer ofta anklagas för att misslyckas; att de tar målen för givna och bidrar till ett problematiskt isärhållande av mål och medel.

\section{PRAKTIKUTVECKLANDE FORSKNING}

Carlgren (2010) framhåller att den ökade betoningen på systematiska översikter riskerar att förstärka det utifrånperspektiv som präglar forskningen om lärares arbete. Problemet är enligt Carlgren att den universitetsbaserade forskningen har distanserat sig från professionens frågor och att det därför saknas en motsvarighet till den kliniska forskning som spelar en central roll inom det medicinska området. Men det är inte primärt mer RCT:er som betraktas som lösningen. Carlgren förordar istället så kallade praktikutvecklande 
ansatser. Enligt Carlgren (2011) utmärks praktikutvecklande ansatser av att vara: (1) kollaborativa — forskare och lärare samverkar för att utforska frågor som är centrala för professionen; (2) intervenerande—något förändras eller prövas i undervisningen samtidigt som lärandet utvärderas; (3) iterativaforskningsprocessen utmärks av återkommande cykliska förlopp under vilka undervisningen justeras och anpassas. Learning study och aktionsforskning utgör exempel på praktikutvecklande ansatser som tillämpas i den svenska skolan och förskolan.

Carlgren $(2011,2010)$ argumenterar för att praktikutvecklande forskning är nödvändig för att lärare ska kunna utveckla och förbättra undervisningen. SKOLFI (2015c) för liknande resonemang och poängterar att förekomsten av svensk praktikutvecklande 4 forskning är av avgörande betydelse för möjligheterna att genomföra sitt uppdrag. SKOLFI har därför förordat inrättandet av ett nytt vetenskapsområde, för Lärande och utbildning, i syfte att stärka denna forskningsinriktning. Givetvis kan det behövas satsningar för att praktikutvecklande ansatser på sikt ska kunna bilda ett relevant underlag för institutets översikter. Men en minst lika viktig fråga är huruvida SKOLFI:s syntesmetoder är anpassade för att inkludera just denna kategori av studier.

Undersökningar visar att DCU i huvudsak har en aggregativ inriktning; de systematiska översikter som har genomförts bygger nästan uteslutande på kvantitativa studier från anglosaxiska länder, främst experimentella designer från USA (Levinsson, 2015; Levinsson \& Prøitz, 2017). Översikterna drivs genomgående av frågor som rör effekter eller orsaker, vilket för DCU tycks medföra en aggregativ logik genom hela utförandet, inklusive urvalet av studier, vilket gör att praktikutvecklande ansatser konsekvent väljs bort. Dyssegaard, Søgaard Larsen och Tiftikci (2013) översikt utgör ett belysande exempel på hur praktikutvecklande forskning exkluderas:

Studier der alene anvender metoder fra aktionsforskning, etnografien eller holdningsundersøgelser (views studies) kan ikke bidrage med sådan viden. Det er derfor blevet besluttet, at studier, der alene anvender designene: etnografi, aktionsforskning eller holdningsundersøgelse, ikke indgår i scopet. (s. 26)

Det finns flera anledningar till varför praktikutvecklande forskning inte anses lämpa sig för konventionella syntesformat (jfr Levinsson, 2015). Jämfört med de experimentella studier som prioriteras i aggregativa översikter finns det betydande skillnader vad det gäller kunskapsintresse och studiedesign (Carlgren, 2011, 2010). Till skillnad från RCT:er syftar praktikutvecklande ansatser överlag inte till att utveckla kunskap om orsakssamband som kan säkerställas i statistisk mening. Enligt Carlgren (2011) kännetecknas dessa studier istället ofta av ett praktiskt intresse som rör möjliga samband mellan undervisning och lärande. Den karaktäristiska designen med cykliska förlopp 
syftar dessutom till att gradvis förfina arbetssätt och metoder. Det är alltså inga "statiska" interventioner som utvärderas där lärare och elever fördelas till experiment- och kontrollgrupp via randomiserade urval. De studier som genomförs inom exempelvis aktionsforskning eller learning study framstår därmed som bristfälliga i den kvalitetsbedömning som avser att undvika olika former av "bias" (jfr Gough m.fl., 2012a, s. 62).

Cheung och Wongs (2014) systematiska översikt av learning study och lesson study baseras på aggregativa metoder för att utvärdera huruvida dessa båda studiedesigner fungerar. Även om syntesen demonstrerar positiva effekter för såväl lärare som elever, drar Cheung och Wong slutsatsen att framtida studier "should be conducted with more representative samples to confirm the effectiveness of Lesson Study and Learning Study. Proper randomization techniques need to be used, clearly described, and fully reported" (s. 147). Vidare konstaterar Cheung och Wong att det är olyckligt att en metaanalys inte har kunnat utföras eftersom studierna inom området är alldeles för heterogena. En likartad problematik har identifierats vad det gäller aktionsforskning och har fått enskilda forskningsmiljöer att betvivla om systematiska översikter alls är möjliga inom området (Waterman, Tillen, Dickson \& de Koning, 2001). Frågan är dock om det är realistiskt att vänta sig att forskningen blir mer homogen i takt med att praktikutvecklande ansatser ökar i skolan och förskolan. En motsatt utveckling är inte orimlig givet alla nivåer, ämnen och mål som skolväsendet omfattar, och i en uppbyggnadsfas finns det sannolikt multipla angelägna frågor att belysa. En annan viktig aspekt att beakta är vad en rörelse mot tekniska intressen och standardisering "gör" med den praktikutvecklande forskningen, inte minst vad det gäller professionens inflytande och ansatsernas följsamhet mot undervisningens särdrag.

Konfigurativa översikter framstår som ett lämpligare alternativ för att syntetisera heterogen praktikutvecklande forskning och kan dessutom inbegripa de kvalitetskriterier som håller på att utvecklas inom området (jfr Gutiérrez \& Penuel, 2014). Till exempel har Waterman m.fl. (2001) genomfört en översikt av hur aktionsforskning kommer till uttryck inom vårdområdet $\mathrm{i}$ Storbritannien. Översikten betecknas som en interpretative review, vilket vid tidpunkten var ett etablerat begrepp för det aggregativa formatets motpol (jfr Gough \& Elbourne, 2002). Waterman m.fl. (2001) motiverar översikten med att aktionsforskning har fått stort genomslag $\mathrm{i}$ praktiken, men att kunskapen tenderar att åsidosättas inom evidensbaserad vård. Totalt ingår 59 studier av skiftande karaktär vilka syntetiseras i två steg. Det första steget har ett narrativt angreppssätt och utforskar vilka syften, motiv, frågor och resultat som presenteras i studierna. Det andra steget baseras på metaetnografi för att belysa aktionsforskningens styrkor och svagheter. Waterman m.fl. (2011) hävdar att översikten är av betydelse för en rad olika parter eftersom resultaten ger insikt $i$ hur aktionsforskning kan 
tillämpas och utvecklas inom vårdsektorn. Men resultaten belyser också frågor av direkt praktisk relevans för olika yrkeskategorier. Baserat på syntesen presenterar Waterman m.fl. dessutom 20 frågor som anses vara särskilt anpassade för att kvalitetsbedöma aktionsforskningsstudier.

Konfigurativa översikter kan alltså ses som viktiga för att SKOLFI ska kunna inkludera praktikutvecklande forskning och därigenom ge lärare goda försättningar att utveckla och förbättra undervisningen. Dessutom kan konfigurativa översikter ge såväl lärare och forskare som andra parter värdefull kunskap om hur praktikutvecklande ansatser kan tillämpas och utvecklas inom skolan och förskolan. Konfigurativa översikter kan följaktligen betraktas som en strategi för SKOLFI att stärka denna forskningsinriktning.

\section{FORSKNINGENS ROLL I PRAKTIKEN}

Aggregativa översikter baseras enligt Gough m.fl. (2012b) på antagandet om att forskning kan och bör spela en teknisk roll i praktiken. Detta antagande har varit föremål för omfattande debatt i forskningslitteraturen (Biesta, 2007; Bridges, 2008; Evaldsson \& Nilholm, 2009; Hammersley, 2004). Kritiker hävdar bland annat att försöken att göra forskning mer användbar för lärare genom att översätta resultaten till praktiska riktlinjer inte har bidragit till att forskningen har tagit sig in i skolan och förskolan. Evaldsson och Nilholm (2010) ställer retoriskt frågan "var finns evidensen för evidensrörelsens anspråk?" (s. 321), och efterlyser på så vis empiriska belägg för att den ökade betoningen på evidensbasering har bidragit till att förbättra undervisningen (jfr Hammersley, 2009).

En väg bort från kontroverserna kring vilken roll forskning kan och bör spela i undervisningen, och som kanske också har potential att göra systematiska översikter mer relevanta, är att inta en pluralistisk hållning $\mathrm{i}$ denna fråga. Biesta (2007) menar att forskning, vid sidan av att ge praktisk vägledning angående metoder och arbetssätt, även kan få lärare att se undervisningen ur nya perspektiv och frigöra dem från det som framstår som irrationellt i verksamheten. Vid sidan av att spela en teknisk roll menar alltså Biesta att forskning även kan fylla upplysande och kritiska funktioner.

SKOLFI (2018) framhåller att systematiska översikter inte ska betraktas som "manualer att följa till punkt och pricka" och "beroende på översiktens karaktär kan användningen också se olika ut"; vissa format anses exempelvis främst kunna bidra till en djupare förståelse av undervisningen. Därutöver betonar SKOLFI vikten av att lärare granskar arbetssätt och metoder kritiskt för att kunna använda dem på ett konstruktivt sätt $i$ undervisningen. Inom ramen för sitt uppdrag skulle dock SKOLFI kunna understödja sådana granskande aktiviteter på ett mer direkt sätt genom att utarbeta översikter med kritisk inriktning. SKOLFI ska enligt uppdraget ge lärare förutsättningar att 
undervisa med stöd av "vetenskapligt underbyggda metoder och arbetssätt" (SFS 2014:1578, 1 J), och denna skrivning utesluter inte en bred vetenskaplig förankring av undervisningen som också inbegriper kritiska forskningstraditioner.

Dixon-Woods m.fl. (2006) hävdar dock att kritiska intressen överlag har försummats i systematiska översikter. Mot denna bakgrund har DixonWoods m.fl. utvecklat ett konfigurativt format, critical interpretative synthesis (CIS), som är särskilt inriktat på att ifrågasätta "the ways in which the literature constructs its problematics, the nature of the assumptions on the literature draw, or what has influenced proposed solutions" (s. 2). Dixon-Woods m.fl. arbetade fram CIS i samband med en översikt av forskningen kring sårbara gruppers vårdtillgång, och syntesen utmynnar i en konceptuell modell där kandidering anses utgöra ett centralt begrepp för att bättre förstå detta fenomen. Kandidering beskriver hur berättigande till vård förhandlas mellan individ och vårdinstans i en dynamisk process, och genom att uppmärksamma hur sårbarhet uppstår i relation till denna process menar Dixon-Woods m.fl. att bättre rekommendationer kan formuleras till både policy och praktik. Sammantaget belyser översikten, liksom andra CIS (t.ex. Entwistle, Firnigl, Ryan, Francis \& Kinghorn, 2012), att den praktiska relevansen av kritiska översikter kan vara betydande.

Det är emellertid svårt att identifiera renodlade exempel på CIS som rör undervisning. ${ }^{5}$ Men forskningen kring formativ bedömning kan bilda utgångspunkt för att belysa kritiska översikters relevans för SKOLFI:s uppdrag. Inom detta område finns det ett stort antal översikter som främst utvärderar effekterna av formativ bedömning (t.ex. Moyles \& Yates, 2003; Randel m.fl., 2011; Sebba m.fl., 2008). Men det finns också ett par översikter, om än informella, som påminner om CIS i det avseendet att forskningen granskas kritiskt (Bennet, 2011; Dunn \& Mulvenon, 2009). Exempelvis identifierar Bennets (2011) översikt en rad problem med studierna inom området. Bennet hävdar bland annat att det vetenskapliga stödet för formativ bedömning är bristfälligt och att formativ bedömning tenderar att behandlas som generella strategier avskilda från den undervisningskontext som lärare verkar i. Mot bakgrund av problemen drar Bennet slutsatsen att formativ bedömning "is both conceptually and practically still a work-in-progress. That fact means we need to be more sensible in our claims about it, as well as in our expectations for it" (s. 21).

Det skulle också vara möjligt att genomföra en konfigurativ översikt som specifikt inkluderar de primärstudier som anlägger kritiska perspektiv på formativ bedömning. Ett exempel på översiktsfråga skulle kunna vara: "vilka problem kan uppstå när formativ bedömning ligger till grund för genomförande av undervisning?” Inom området finns det ett växande antal fallstudier som uppmärksammar att användningen av formativ bedömning kan ge upphov till vad Torrance (2007) benämner som "bedömning som 
lärande" (se också Hume \& Coll, 2009; Ferm Almqvist, Vinge, Väkevä \& Zandén, 2016; Torrance, 2012). Torrance (2007) använder beteckningen "bedömning som lärande" för att beskriva hur formativ bedömning kan ge upphov till instrumentella undervisningskulturer, där synliggörandet av mål och kriterier förefaller att prägla elevernas lärandeerfarenheter på bekostnad av ämnesinnehållet (jfr Hume \& Coll, 2009). Därutöver finns det studier som visar att formativ bedömning kan tillämpas "lärarcentrerat", "ytligt", "konformativt", "bokstavligt", "konvergent" och "deformativt" (Black \& Wiliam, 2009; Marshall \& Drummond, 2006; Torrance \& Pryor, 2001; Torrance, 2012). Huruvida dessa begrepp representerar kvalitativt skilda problem i förhållande till "bedömning som lärande" är upp till den skisserade konfigurativa översikten att utforska (jfr Gough \& Thomas, 2012, s. 52).

Även om denna översikt, liksom Bennet (2011), inte utmynnar i riktlinjer och handledningar ska den praktiska relevansen inte underskattas (jfr Biesta, 2007). Genom kritiska översikter kan lärare upplysas om att formativ bedömning kan användas på en rad olika sätt, varav en del av dessa inte tycks vara särskilt gynnsamma för lärande, och dessutom erhålla en beredskap att förändra undervisningen. Lärare skulle sannolikt också ges bättre förutsättningar att hantera de förväntningar och krav på förbättrade kunskapsresultat som ofta kommer i kölvattnet av olika satsningar på formativ bedömning.

Konfigurativa format kan alltså betraktas som avgörande för att SKOLFI:s översikter ska kunna inbegripa kritiska forskningstraditioner och därmed få betydelse för lärare på sätt som går utöver tillämpandet av "färdiga" metoder och arbetssätt. En bred vetenskaplig underbyggnad av undervisningen, som innefattar forskning med potential att spela en frigörande roll i praktiken, understödjer dessutom den kritiska granskning som SKOLFI framhåller som viktig.

\section{GRÄNSER FÖR KONFIGURATIVA ÖVERSIKTER}

I ljuset av SKOLFI:s uppdrag har föreliggande artikel drivit tre huvudsakliga argumentationslinjer som alla leder till slutsatsen att delar av institutets arbete med systematiska översikter bör baseras på konfigurativa angreppssätt. Mycket av argumentationen bottnar i antagandet att pluralism är att föredra när det gäller frågan om vad som ska räknas som värdefull forskning för lärare och på vilka sätt som den kan göra skillnad för undervisningen.

If there are different ways to understand the world, and if there are different forms that make such understanding possible, then it would seem to follow that any comprehensive effort to understand the processes and 
outcomes of schooling would profit from a pluralistic rather than a monolithic approach to research. (Eisner, 1993, s. 8)

De argument som framförts ifrågasätter således inte relevansen av aggregativa översikter. Aggregativa översikter kan svara på frågor som av förklarliga skäl inte är särskilt väl lämpade för konfigurativa format (jfr Gough m.fl., 2012a). Det är dock viktigt att understryka att en ökad betoning på konfigurativa översikter går utöver de ursprungliga politiska intentionerna med SKOLFIatt systematiska översikter främst ska bidra till förbättringar av kunskapsresultaten. Konfigurativa format skulle underlätta för SKOLFI att utarbeta systematiska översikter mer följsamt mot läraryrkets och undervisningens inneboende komplexitet. Därmed inte sagt att konfigurativa översikter ensamma kan tillhandahålla den kunskap som lärare behöver. Med hjälp av konfigurativa översikter skulle SKOLFI framförallt ges bättre möjligheter att understödja omdömen om vad som är utbildningsmässigt önskvärt, inkludera studier från praktikutvecklande ansatser, samt förmedla kunskap som kan spela en kritisk roll i undervisningen.

\section{NOTER}

Under möten med Vetenskapsrådets så kallade SKOLFORSK-projekt gav ansvariga för utredningen uttryck för att SKOLFI:s myndighetsinstruktion avser att svara mot hur undervisning är reglerat i skollagen.

2 Översikten framstår dock som relevant för att sätta olika innebörder av medborgarfostran i relation till de pedagogiska aktiviteter som har studerats inom området. Ett kombinerat aggregativt och konfigurativt format kan alltså vara passande för att understödja diskussion kring vilka innebörder av målen som är önskvärda i nära anslutning till de medel som finns tillgängliga (jfr Biesta, 2007).

${ }^{3}$ Inom medicin- och vårdområdet finns det exempel på systematiska översikter som avser att informera professionellas omdömen på ett indirekt sätt. Strech och Sofaer (2012) har exempelvis utvecklat ett översiktsformat för att syntetisera undersökningar som baseras på argumentation. För att illustrera formatet använder Strech och Sofaer litteratur som belyser olika etiska frågor. Men översikten syftar inte till att komma fram till ett slutgiltigt svar på de etiska frågorna, utan det är argumenten för och emot olika ståndpunkter som syntetiseras.

${ }^{4}$ SKOLFI använder "praktiknära" som beteckning för denna forskningsinriktning. SKOLFI:s (2015c, s.4) definition av praktiknära forskning är emellertid identisk med vad Carlgren (2011) avser med praktikutvecklande forskning.

${ }^{5}$ Inom högre utbildning har dock Franqueira och Tunnicliffe (2015) genomfört en översikt av så kallat "flippat klassrum" som är inspirerad av CIS-formatet. 


\section{REFERENSER}

Barnett-Page, Elaine \& Thomas, James (2009). Methods for the synthesizing of qualitative research: A critical review. BMC Medical Research Methodology, 9(59), 1-11.

Bennett, Randy E. (2011). Formative assessment: A critical review. Assessment in Education, 18(1), 5-25.

Biesta, Gert (2007). Why 'what works' won't work: Evidence-based practice and the democratic deficit in educational research. Educational Theory, 57(1), 1-22.

Black, Paul \& Wiliam, Dylan (2009). Developing the Theory of Formative Assessment. Educational Assessment, Evaluation and Accountability, 21(1), 5-31.

Bohlin, Ingemar (2010). Systematiska översikter, vetenskaplig kumulativitet och evidensbaserad pedagogik. Pedagogisk Forskning i Sverige, 15(2), 164-186.

Bohlin, Ingemar (2011). Evidensbaserat beslutsfattande i ett vetenskapsbaserat samhälle. Om evidensrörelsens ursprung, utbredning och gränser. I Ingemar Bohlin \& Morten Sager (Red.), Evidensens många ansikten (31-68). Lund: Arkiv Förlag.

Bohlin, Ingemar (2012). Formalizing syntheses of medical knowledge: The rise of metaanalysis and systematic reviews. Perspectives on Science, 20(3), 273-309.

Bridges, David (2008). Evidence-based reform in education: A response to Robert Slavin. European Educational Research Journal, 7(1), 129-133.

Campbell Collaboration (2014). Campbell Systematic Reviews: Policies and Guidelines Campbell Systematic Reviews 2014: Supplement 1.

Carlgren, Ingrid (2010). Den felande länken: Om frånvaron och behovet av klinisk utbildningsvetenskaplig forskning. Pedagogisk. Forskning i Sverige, 15(4), 295-306.

Carlgren, Ingrid (2011). Forskning ja, men vilken slags och i vilket syfte? Om avsaknaden och behovet av en "klinisk" mellanrumsforskning. Pedagogisk forskning, 15(4). 65-79.

Cheung, Wai M. \& Wong, Wing Y. (2014). Does lesson study work? International Journal for Lesson and Learning Studies, 3(2), 137-149.

Clegg, Sue (2005). Evidence-based practice in educational research: a critical realist critique of systematic review. British Journal of Sociology of Education 26(3), 415-428.

Dixon-Woods, Mary, Cavers, Debbie, Agarwal, Shona, Annandale, Ellen, Arthur, Antony, Harvey, Janet, ... Sutton, Alex J. (2006). Conducting a critical interpretive synthesis of the literature on access to healthcare by vulnerable groups. BMC Medical Research Methodology, 6(35), 1-13.

Donnelly, James F. (1999). Schooling Heidegger: On being in teaching. Teaching and Teacher Education, 15(8), 933-949.

Dunn, Karee E. \& Mulvenon, Sean W. (2009). A critical review of research on formative assessment: The limited scientific evidence of the impact of formative assessment in education. Practical Assessment, Research \& Evaluation, 14(7). 
Dyssegaard, Camilla B., Søgaard Larsen, Michael \& Tiftikci, Neriman (2013). Effekt og padagogisk indsats ved inklusion af born med sarlige behov i grundskolen. Copenhagen: Danish Clearinghouse for Educational Research, Department of Education, Aarhus University.

Eisner, Elliot W. (1993). Forms of understanding and the future of educational research. Educational Researcher, 22(7), 5-11.

Elbaum, Batya, Vaughn, Sharon, Hughes, Marie \& Watson Moody, Sally (1999). Grouping practices and reading outcomes for students with disabilities. Exceptional Cbildren, 65(3), 399-415.

Entwistle, Vikki A., Firnigl, Danielle, Ryan, Mandy, Francis, Jillian J. \& Kinghorn, Phillip (2012). Which experiences of health care delivery matter to service users and why? A critical interpretive synthesis and conceptual map. Journal of Health Services Research \& Policy, 17(2), 70-78.

Evaldsson, Ann-Carita \& Nilholm, Claes (2009). Evidensbaserat skolarbete och demokrati: Mobbning som exempel. Pedagogisk Forskning i Sverige, 14(4), 503-511.

Evaldsson, Ann-Carita \& Nilholm, Claes (2010). Var finns evidensen för evidensrörelsens anspråk? Pedagogisk Forskning i Sverige, 15(4), 321-326.

Ferm Almqvist, Cecilia, Vinge, John, Väkevä, Lauri \& Zandén, Olle (2016). Assessment as learning in music education: The risk of "criteria compliance" replacing "learning" in the Scandinavian countries. Research Studies in Music Education, 39(1), 3-18.

Franqueira, Virginia N. L. \& Tunnicliffe, Peter (2015). To flip or not to flip: A critical interpretive synthesis of flipped teaching. I Vladimir L. Uskov, Robert J. Howlett \& Lakhmi C. Jain (Red.), Smart Education and Smart e-Learning (57-67). Heidelberg: Springer International Publishing.

Geboers, Ellen, Geijsel, Femke, Admiraal, Wilfried \& ten Dam, Geert (2013). Review of the Effects of Citizenship Education. Educational Research Review 9, 158-173.

Gough, David (2004). Systematic research synthesis. I Gary Thomas \& Richard Pring (Red.), Evidence-based practice in education (44-62). Buckingham: Open University Press.

Gough, David \& Elbourne, Diana (2002). Systematic research synthesis to inform policy, practice and democratic debate. Social Policy and Society, 1(3), 225-236.

Gough, David, Oliver, Sandy \& Thomas, James (Red.). (2012a). An introduction to systematic reviews. London: Sage.

Gough, David, Oliver, Sandy \& Thomas, James (2012b). Clarifying differences between review designs and methods. Systematic Reviews, 1(28), 1-9.

Gough, David \& Thomas, James (2012). Commonality and diversity in reviews. I David Gough, Sandy Oliver \& James Thomas (Red.), An introduction to systematic reviews (35-65). London: Sage. 
Gough, David, Oliver, Sandy \& Thomas, James (2013). Learning from research: systematic reviews for informing policy decisions: a quick guide. A paper for the Alliance for Useful Evidence. London: Nesta.

Greenhalgh, Trisha, Robert, Glenn, Macfarlane, Fraser, Bate, Paul, Kyriakidou, Olympia \& Peacock, Richard (2005). Storylines of research in diffusion of innovation: A meta-narrative approach to systematic review. Social Science \& Medicine 61(2), 417-430.

Gutiérrez, Kris D. \& Penuel, William R. (2014). Relevance to Practice as a Criterion for Rigor. Educational Researcher, 43(1), 19-23.

Hammersley, Martyn (2004). Some questions about evidence-based practice in education. I Gary Thomas \& Richard Pring (Red.), Evidence-based practice in education (133-149). Buckingham: Open University Press.

Hammersley, Martyn (2009). What is evidence for evidence-based practice? I. HansUwe Otto, Andreas Polutta \& Holger Ziegler (Red.), Evidence-based practicemodernising the knowledge base of social work (139-150). Opladen: Budrich.

Hansen, Hanne F. \& Rieper, Olaf (2009). The evidence movement. The development and consequences of methodologies in review practices. Evaluation, 15(2), 141-163.

Higgins, Julian P. T., Altman, Douglas G. \& Sterne, Jonathan A. C. (2011). Chapter 8: Assessing risk of bias in included studies. I Julian P. T. Higgins \& Sally Green (Red.), Cochrane Handbook for Systematic Reviews of Interventions Version 5.1.0 (rev. March 2011). The Cochrane Collaboration.

Hume, Anne \& Coll, Richard K. (2009). Assessment of learning, for learning, and as learning: New Zealand case studies. Assessment in Education: Principles, Policy \& Practice, 16(3), 269-290.

Levinsson, Magnus (2015). Kartläggning och sammanställning av forskning $i$ Norden. Stockholm: Vetenskapsrådet.

Levinsson, Magnus (2017). Kan och bör systematiska översikter adressera frågor om vad som är utbildningsmässigt önskvärt? Nordisk Tidskrift för Allmän Didaktik, 3(1), 86-92.

Levinsson, Magnus \& Prøitz, Tine S. (2017). The (non-)use of configurative reviews in education. Education Inquiry, 8(3), 209-231.

Marshall, Bethan \& Drummond, Mary J. (2006). How teachers engage with assessment for learning: Lessons from the classroom. Research Papers in Education, 21(2), 133-149.

Moos, Lejf (2006). A real change or a change in rhetoric? Comments to two OECD reviews on educational research: United Kingdom in 2002 and Denmark in 2004. I Tom Schuller, Wim Jochems, Lejf Moos \& Agnes Van Zanten, Evidence and policy research. European Educational Research Journal 5(1), 57-61. doi:10.2304/eerj.2006.5.1.57

Moyles, Janet \& Yates, Richard (2003). What is known about successful models of formative 
assessment for trainee teachers during school experiences and what constitutes effective practice? Research Evidence in Education Library. London: EPPI-Centre.

Nilholm, Claes \& Göransson, Kerstin (2015). Forskningen om inkludering-en SMART översikt. Stockholm: Vetenskapsrådet.

Noblit, George W. \& Hare, Dwight R. (1988). Meta-ethnography: Synthesizing qualitative studies. Beverly Hills, CA: Sage.

O’Connor, Denise, Green, Sally \& Higgins, Julian P. T. (2011). Chapter 5: Defining the review question and developing criteria for including studies. I Julian P. T. Higgins \& Sally Green (Red.). Cochrane Handbook for Systematic Reviews of Interventions Version 5.1.0 (rev. March 2011). The Cochrane Collaboration.

Organisation for Economic Co-operation and Development (2003). New challenges for educational research. Paris: CERI.

Organisation for Economic Co-operation and Development (2004a). National review on educational R \& D: Examiners' report on England. Paris: CERI.

Organisation for Economic Co-operation and Development (2004b). National review on educational R \& D: Examiners' report on Denmark. Paris: CERI.

Organisation for Economic Co-operation and Development (2007). Evidence in Education. Linking research and policy. Paris: CERI.

Paterson, Barbara L., Thorne, Sally E., Canam, Connie \& Jillings, Carol (2001). Metastudy of qualitative health research: A practical guide to meta-analysis and meta-synthesis. Thousand Oaks, CA: Sage.

Petticrew, Mark (2015). Time to rethink the systematic review catechism? Moving from 'what works' to 'what happens'. Systematic reviews, 4(1), 1-9.

Petticrew, Mark \& Roberts, Helen (2006). Systematic reviews in the social sciences. Malden: Blackwell Publishers.

Prøitz, Tine S. (2015). Metoder for systematiske kunnskapsoversikter. Stockholm: Vetenskapsrådet.

Randel, Bruce, Beesley, Andrea D., Apthorp, Helen, Clark, Tedra F., Wang, Xin, Cicchinelli, Louis F. \& Williams, Jean M. (2011). Classroom assessment for student learning: The impact on elementary school mathematics in the central region (NCEE 20114005). Washington, DC: National Center for Education Evaluation and Regional Assistance, Institute of Education Sciences, U.S. Department of Education.

Regeringsdirektiv (Dir. 2014:7). Inrättande av ett Skolforskningsinstitut. Stockholm: Utbildningsdepartementet.

Scott, David \& Lawson, Helen (2001). Citizenship education: Models and discourses. I Alistar Ross (Red.), Learning for a democratic Europe (349-356). London: Children's Identity and Citizenship in Europe.

Sebba Judy, Crick, Ruth D., Yu, Guoxing, Lawson, Hilary, Harlen, Wynne \& Durant, Keren (2008). Systematic review of research evidence of the impact on students in secondary 
schools of self and peer assessment (Technical report). Research Evidence in Education Library. London: EPPI-Centre, Social Science Research Unit, Institute of Education, University of London.

SFS 2014:1578. Förordning med instruktion för Skolforskningsinstitutet. Stockholm: Utbildningsdepartementet.

Skolforskningsinstitutet (2015a, 23 mars). @FrkPernilla Under uppbyggnadsfasen pågår metodutveckling och behovsfångst innan systematiska kunskapssammanställningar kan göras. (Twitterinlägg). Hämtad från https://twitter.com/skolfi/status/580018730685632512

Skolforskningsinstitutet (2015b). Arsredovisning 2015. Solna: Skolforskningsinstitutet.

Skolforskningsinstitutet (2015c). Behovet av praktiknära forskning inom det utbildningsvetenskapliga fältet. Skrivelse till Utbildningsdepartementet. Inspel till forskningspropositionen (2015-11-04). Solna: Skolforskningsinstitutet.

Skolforskningsinstitutet (2016a, 3 februari). Systematiska översikter är ett metodutvecklingsområde. @skolfi ser@SBU_se som en systermyndighet. Viktigt med samarbete. (Twitterinlägg). Hämtad från https://twitter.com/skolfi/status/694843790922772481

Skolforskningsinstitutet (2016b, 28 januari). Professor of Evidence-informed Policy and Practice David Gough @EPPICentre is visiting@skolfi to discuss methods of systematic reviews. (Twitterinlägg). Hämtad från https://twitter.com/skolfi/status/692640064682250240

Skolforskningsinstitutet (2016c). Arsredovisning 2016. Solna: Skolforskningsinstitutet.

Skolforskningsinstitutet (2017). Arsredovisning 2017. Solna: Skolforskningsinstitutet.

Skolforskningsinstitutet (2018). Utveckla undervisningen med stöd av systematiska översikter. Hämtad 2018-03-15 från http://www.skolfi.se/forskningssammanstallningar/utveckla-undervisningen-med-stod-av-systematiskaoversikter/

Snilstveit, Birte, Oliver, Sandy \& Vojtkova, Martina (2012). Narrative approaches to systematic review and synthesis of evidence for international development policy and practice. Journal of Development Effectiveness, 4(3), 409-429.

SOU 2009:94. Att nå ut och nå ända fram. Stockholm: Utbildningsdepartementet.

Strech, Daniel \& Sofaer, Neema (2012). How to write a systemtic review of reasons. Journal of Medical Ethics, 38(2), 121-126.

Swanson, Elizabeth A., Hairrell, Angela, Shawn, Kent, Ciullo, Stephen, Wanzek, Jeanne A. \& Vaughn, Sharon (2014). A synthesis and meta-analysis of reading interventions using social studies content for students with learning disabilities. Journal of Learning Disabilities, 47(2), 178-195.

Torgerson, Carole (2003). Systematic reviews. London: Continuum International. 
Torrance, Harry (2007). Assessment "as" learning? How the use of explicit learning objectives, assessment criteria and feedback in post-secondary education and training can come to dominate learning. Assessment in Education: Principles, Policy \& Practice, 14(3), 281-294.

Torrance, Harry (2012). Formative assessment at the crossroads: Conformative, deformative and transformative assessment. Oxford Review of Education, 38(3), 323342.

Torrance, Harry \& Pryor, John (2001). Developing formative assessment in the classroom: Using action research to explore and modify theory. British Educational Research Journal, 27(5), 615-631.

Utredningen om inrättandet av ett Skolforskningsinstitut (U2014:02). Delrapport. Stockholm: Utbildningsdepartementet.

Vetenskapsrådet (2015). Forskning och skola i samverkan. Kartläggningar av forskningsresultat med relevans för praktiskt arbete $i$ skolväsendet. Stockholm: Vetenskapsrådet.

Waterman, Heather, Tillen, Dominique, Dickson, Rumona \& De Koning, Korrie (2001). Action research: a systematic review and guidance for assessment. Health Technology Assessment, 5(23), 1-166.

Wendt, Rikke E. (2016). Systematiske reviews og kvalitativ forskning. Inddragelse af kvalitativ forskning $i$ systematiske reviews på uddannelsesomradet. Ph.d.-afhandlng ved Aarhus Universitet, Faculty of Arts. Danmarks institut for Pædagogik og Uddannelse.

Westhorp, Gill, Walker, Bill, Rogers, Patricia, Overbeeke, Nathan, Ball, Daniel \& Brice, Graham (2014). Enhancing community accountability, empowerment and education outcomes in low and middle-income countries: A realist review. London: EPPI-Centre, Social Science Research Unit, Institute of Education, University of London.

What Works Clearinghouse (u.å.). Procedures and standards handbook (version 3.0). Hämtad 2017-03-28 från https://ies.ed.gov/ncee/wwc/Handbooks 